\title{
Day-time variations of foF2 connected to strong earthquakes
}

\author{
E. V. Liperovskaya ${ }^{1}$, V. V. Bogdanov ${ }^{2}$, P.-F. Biagi ${ }^{3}$, C.-V. Meister ${ }^{4}$, V. A. Liperovsky ${ }^{1}$, and M. V. Rodkin ${ }^{5}$ \\ ${ }^{1}$ Institute of Physics of the Earth of the Russian Academy of Sciences, Bolshaya Gruzinskaya 10, 123995 Moscow, Russia \\ ${ }^{2}$ Institute of Cosmophysical Research and Radio Wave Propagation, Far Eastern Branch of the Russian Academy of Sciences, \\ 684034 Petropavlovsk-Kamchatsky, Russia \\ ${ }^{3}$ Physics Department, University of Bari, 70126 Bari, Italy \\ ${ }^{4}$ Technische Universität Darmstadt, Institut für Kernphysik, Schlossgartenstr. 9, 64289 Darmstadt, Germany \\ ${ }^{5}$ Geophysical Centre of the Russian Academy of Sciences, Molodejnaya 3, 117296 Moscow, Russia
}

Received: 7 July 2008 - Revised: 9 December 2008 - Accepted: 17 December 2008 - Published: 19 January 2009

\begin{abstract}
The statistical analysis of the characteristic frequency foF2 of the Earth's ionosphere averaged over midday hours - from 11:00 till 17:00 hLT - is carried out. Disturbances of foF2 connected to earthquakes are considered on the background of seasonal, geomagnetic, 11-years and 27-days solar variations. A special normalized parameter $F$ is introduced, which represents the almost seasonalindependent part of foF2. Days with high solar (Wolf number $>100)$ and geomagnetic $\left(\Sigma K_{p}>30\right)$ activity are excluded from the analysis. Events with magnitude $M>5$, distance from the sounding station $R<500 \mathrm{~km}$ and depth $h<70 \mathrm{~km}$ are taken into account. The superimposed epoches' method is used to determine the temporal dependence of $F$. It is found that $F$ increases about 3-6 days before the earthquakes and then decreases one day - two days before the shock. The decreased values of $F$ continue to exist twothree days after events with $M>5.5$. The obtained phenomenon depends on the magnitude of the earthquake. For events with $M>5.5$, the reliability of the effect is larger than $95 \%$. For data of more than 80 earthquakes in the vicinity of Petropavlovsk-Kamchatsky and more than 200 earthquakes in the vicinity of Tokyo analogous results are obtained.
\end{abstract}

\section{Introduction}

At the beginning of the 1980s, according to the observations of the ionosphere by vertical sounding stations in seismoactive regions of Middle Asia, it was suggested that the crit-

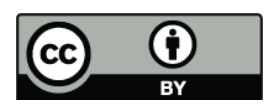

Correspondence to: $\mathrm{C} . \mathrm{-V}$. Meister (c.v.meister@skmail.ikp.physik.tudarmstadt.de) ical frequency foF2, which describes the maximum plasma density in the F-layer, could be sufficiently sensitive to earthquake preparation processes (Gokhberg et al., 1983, 1984, 1987, 1988; Khakimov et al., 1989; Liperovsky et al., 1990). This idea had to be proven and practically applied taking into account the large number of continuously working vertical ionospheric sounding stations localized at different places on Earth, among other in seismo-active areas.

First results of corresponding investigations of the foF2 behaviour at night, considering data of some stations registered in connection with earthquakes with magnitudes $M>4.5$, allowed to make the conclusion that the mean nighttime foF 2 frequency a few days before an earthquake increases. As a rule, during earthquake preparation times, about 2-3 days before the shock, in a broad ionospheric region of $\pm 10^{\circ}$ latitude and $\pm 10^{\circ}$ longitude without or with weak geomagnetic activity, the mean foF 2 value increases. On the other side, there exists a relative minimum of the foF2 value above the epicentral area about one day before the earthquake. It has to be underlined that the above cited works took into account only data of Middle Asia. An increase of foF 2 in the midday time before a few very strong earthquakes was also mentioned in (Ondoh, 2000; Gaivoronskaya, 2005; Korsunova and Hegai, 2005). But in some cases the precursor phenomena were not obtained.

Moreover, in the works (Ondoh, 2000; Silina et al., 2001; Rios at al., 2004; Hobara and Parrot, 2005; Singh et al., 2004) a decrease of the critical foF2 frequency was found before some very strong earthquakes $(M>6)$. Results of the statistical investigations of the foF 2 decrease in the hours after midday before earthquakes with $M>5$ at Taiwan are published in (Liu et al., 2006). In this work, it is shown that the decrease occurs between 12:00 LT and 18:00 LT about $0-5$ days before

Published by Copernicus Publications on behalf of the European Geosciences Union. 


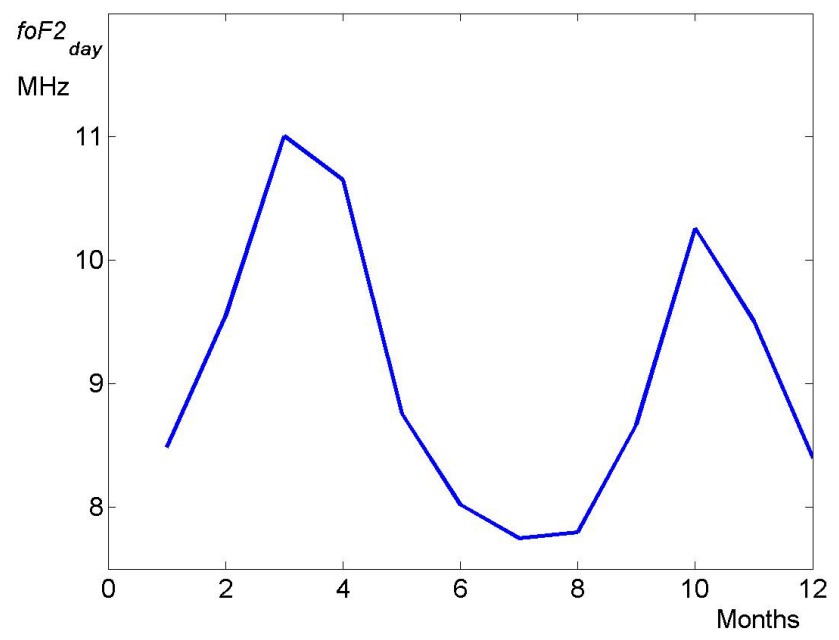

Fig. 1. Seasonal behaviour of foF 2 day according to data of the station "Tokyo" obtained 1957-1990.

the earthquakes. The decrease may amount to $25 \%$. The aim of the present work is the statistical analysis of the foF 2 increase or decrease 3-6 days before the earthquakes. It will be determined, for which magnitudes of the earthquakes and at which distances from the epicentres the phenomenon may be obtained.

\section{Method of analysis}

In the present work, ionospheric phenomena related to strong earthquakes with magnitudes $M>5$ are considered. The distances between the epicentres of the earthquakes and the vertical sounding stations are less than $500 \mathrm{~km}$, and the depths of the epicentres are smaller than $70 \mathrm{~km}$. The data were obtained by the stations "Tokyo" (in Kokubunji, latitude $\varphi=35.7^{\circ} \mathrm{N}$, longitude $\lambda=139.5^{\circ} \mathrm{E}$ ) in $1957-1990$ and "Petropavlovsk-Kamchatsky" on Kamchatka (latitude $\varphi=53.0^{\circ} \mathrm{N}$, longitude $\lambda=158.7^{\circ} \mathrm{E}$ ) in 1968-1995 and published in the internet http://spidr.ngdc.noaa.gov/spidr/.

The day-time ionospheric F-layer forms under the influence of the solar radiation with wavelengths of $14-80 \mathrm{~nm}$ in the neutral atmosphere. Thus, the atmospheric ionization is mainly connected with the ionization of oxygen $\mathrm{O}$ and nitrogen molecules $\mathrm{N}_{2}$. The altitude and the value of the main electron density maximum of the F-layer depend on the competition between the ionization processes by the solar radiation and the recombination. In the present work, temporal mean values of foF 2 are considered, which are found by averaging over five hours. It is natural to chose such time intervals of the day, during which the foF2 values do not change significantly. At sunrise and sunset, the time derivative of foF 2 is very large. Thus, for the analysis one may chose hours around noon or midnight. A preliminary spectral

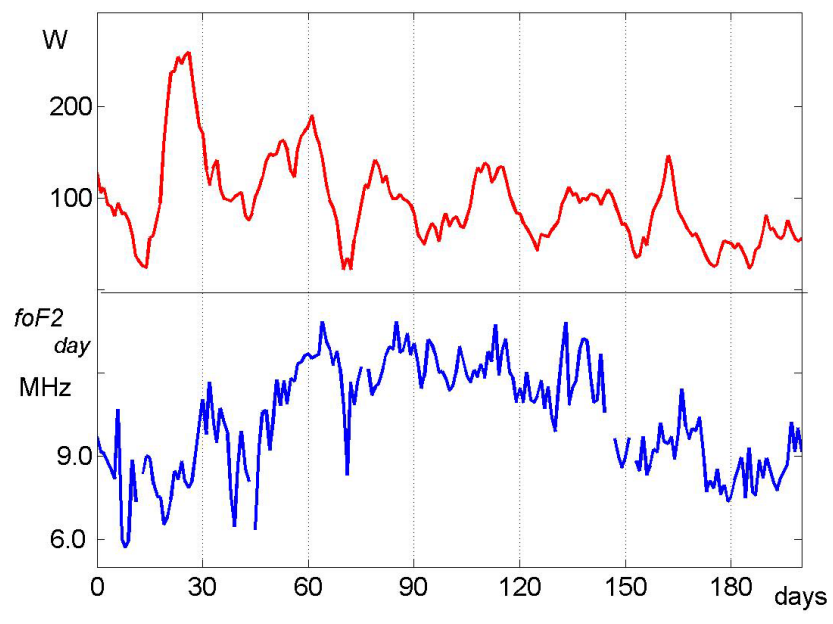

Fig. 2. Comparison of 27-days solar variations and foF 2 day variations. Data of the station "Tokyo" are used.

analysis shows, that seismoionospheric phenomena related to foF 2 variations are more significant in the day-time, possibly due to the fact that the area with maximum plasma ionization is situated at lower altitudes than at other hours. Therefore, for the averaging of the data the day-time between 11:00 LT and 16:00 LT is chosen.

The mean day-time value of foF 2 , foF 2 day possesses a rather difficult seasonal dependence. foF 2 day has two maxima, in spring and in autumn, and two minima, in winter and in summer (see Fig. 1). Besides, variations of the foF 2 day value are influenced by the 11-years and the 27-days solar cycles. Thus, to show lithosphere-ionosphere phenomena on the background of such a seasonal and solar influence is a very difficult task. The 27-days variations are not simple sinusoidal ones (Fig. 2). Moreover, during the increase of the 11 years solar activity the 27-days cycles are more pronounced than during times of the decrease of the solar activity. The maxima of the 27-days solar cycle are observed on various days after the begin of the 27-days solar-day. Thus it is not purposeful to apply a fast Fourier transformation and to suppress the corresponding 27 day harmonic from the foF 2 day data. Therefore, to reduce the influence of the 27 days solar cycle and of the season, further the average value of 15 days (starting with day -7 and ending with day +7 with respect to every analyzed day) is subtracted from the mean foF $2_{\text {day }}$ value. One finds $\Delta f(i)=\mathrm{foF} 2_{\text {day }}(i)-\mathrm{foF} 215$ days $(i)$ (Fig. 3). The short time interval of only 15 days is above all chosen to decrease the influence of the 27-days solar cycle.

After the calculation of the difference $\Delta f(i)$, all days with values larger than $2 \mathrm{MHz}$ are neglected. Such values take place in about $1 \%$ of all days. The main part of these values is related to the strong geomagnetic and solar disturbances, but there are also spikes of unknown reason. The large disturbances are excluded to calculate the mean-square value of 


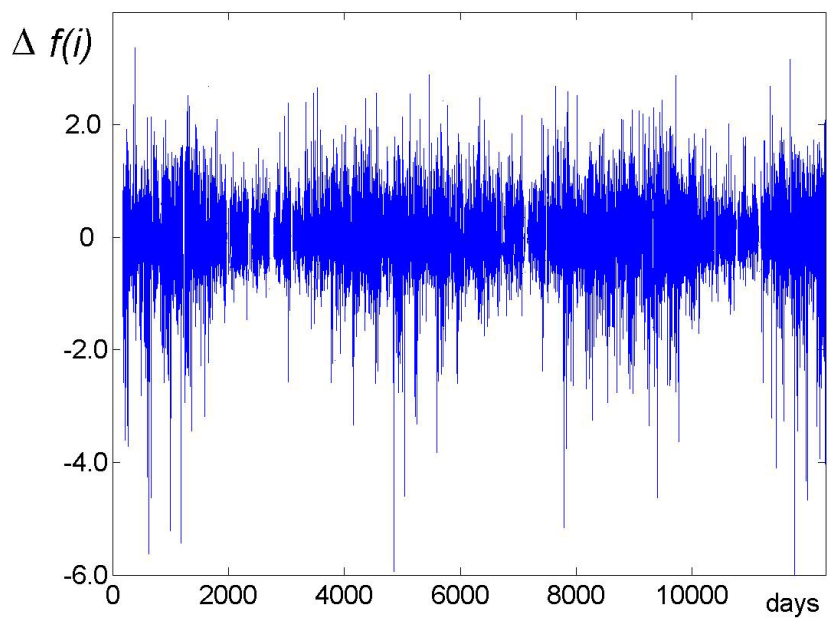

Fig. 3. $\Delta f(i)$-the difference between foF2day value and seasonal run. Results for the station "Tokyo" are presented.

the variation $\Delta f(i)$, that means $\sigma(\Delta f(i))$, more carefully. Further, $\Delta f(i)$ is normalized by $\sigma(\Delta f(i))$. Thus, every day of the analysed time interval is characterized by the normalized function $F(i)=\Delta f(i) / \sigma(\Delta f(i))$.

The ionospheric effects of earthquakes have to be found also on the background of solar and geomagnetic disturbances. Thus only days with not too strong disturbances are taken into account. Of course, there do not exist generally accepted criteria which disturbances should be excluded from the analysis. In the present work days with Wolf numbers $W>100$ are neglected. As known, ionospheric disturbances may continue to exist for days after strong geomagnetic disturbances. Thus, days with $\Sigma K_{p}>30$, and the following day in each case, are not taken into account too. The auroral activity influences the ionosphere above the stations "Tokyo" and "Petropavlovsk-Kamchatsky" differently, as these stations are situated at different latitudes. The condition $\Sigma K_{p}>30$ was chosen to exclude in the case of both sounding stations data registered at days with rather high auroral activity, and to have yet enough remaining data to carry out a statistical analysis. Studying instead of foF2 the Fbehaviour, one nevertheless does not by-pass the whole seasonal influence. But the influence of the season on $F$ is already negligible.

In the analysis, first earthquakes with magnitudes $M>5.5$ are taken into account, which happened at distances from the sounding stations not larger than $500 \mathrm{~km}$ and had a depth of the epicentre not larger than $70 \mathrm{~km}$. Studying earthquake precursor phenomena, one usually uses the Dobrovolsky formula $R=\exp (M) \mathrm{km}$ to estimate the radius of the earthquake preparation area (Dobrovolsky et al., 1979). This formula was proposed for earthquakes occurring in the Earth's core. Independent of the reasons of the seismic phenomena in the ionosphere, if they are electromagnetic or acoustic pulses, the pulses may propagate up into the ionosphere under a tilt

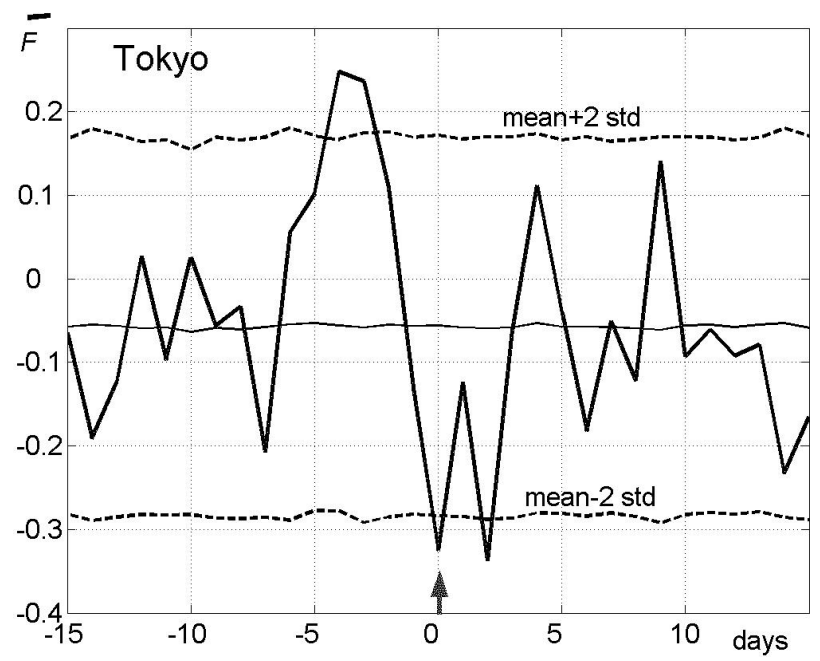

Fig. 4. Result of the application of the superposition of epochs method for the station "Tokyo" $(M>5.5, R<500 \mathrm{~km}, h<70 \mathrm{~km})$. 67 earthquakes are taken into account.

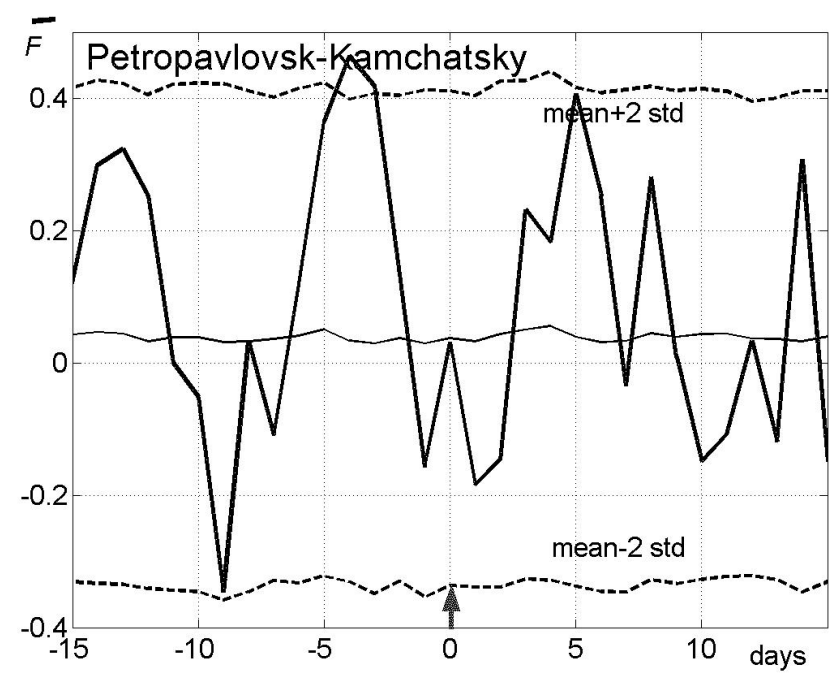

Fig. 5. Result of the application of the superposition of epochs method for the station "Petropavlovsk-Kamchatsky" $(M>5.5$, $R<500 \mathrm{~km}, h<70 \mathrm{~km}) .24$ earthquakes are taken into account.

angle to the verticale. Thus, the radius of the ionospheric precursor may be larger than that found by the Dobrovolsky formula by about $100-200 \mathrm{~km}$. For earthquakes with magnitudes $M=5$ the radius may amount to $350 \mathrm{~km}$. Further, the ionised cloud in the F-region may be displaced by about $100-200 \mathrm{~km}$ due to the neutral winds. Consequently, in the present work, experimental data are analysed which were obtained at a distance of up to $500 \mathrm{~km}$ from the epicentres.

The method of superposition of epoches is applied to the F-values for a time interval of $(-15, \ldots,+15)$ days for both 


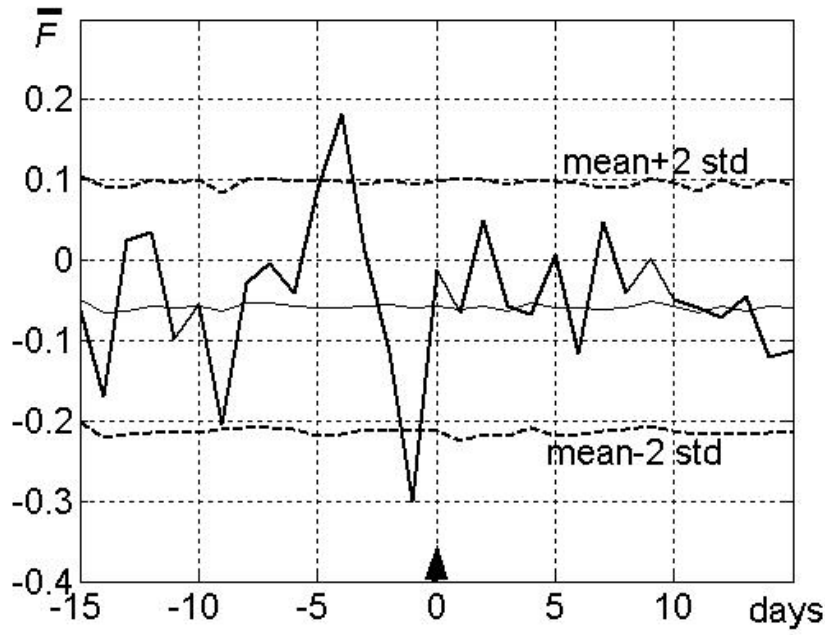

Fig. 6. Result of the application of the superposition of epochs method for the station "Tokyo" $(5.0<M \leq 5.5, R<500 \mathrm{~km}$, $h<70 \mathrm{~km}) .129$ earthquakes are taken into account.

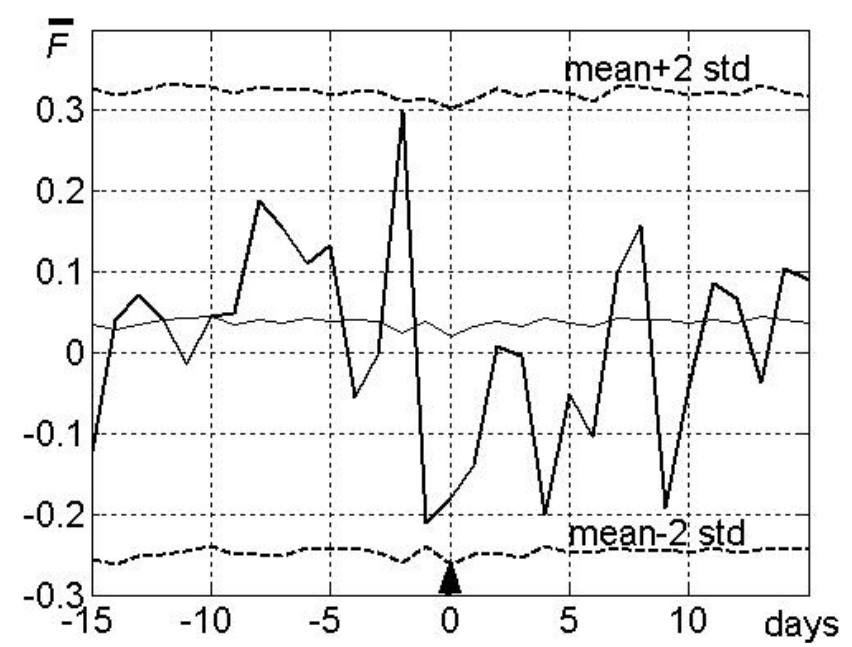

Fig. 7. Result of the application of the superposition of epochs method for the station "Petropavlovsk-Kamchatsky" $(5.0<M \leq 5.5$, $R<500 \mathrm{~km}, h<70 \mathrm{~km}) .44$ earthquakes are taken into account.

vertical sounding stations separately. So the function $\bar{F}$ is found. For earthquakes near "Tokyo" (Fig. 4) an increase of $\bar{F}$ is obtained (bold face line) for the days $(-6)-(-2)$, and on the days $(-4,-3)$, the value of $\bar{F}$ is larger than $95 \%$ of the upper boundary of the interval of reliability (dashed line). The thin full line gives the mean value of $\bar{F}$. In the case of "Tokyo", the decrease of $\bar{F}$ after the earthquakes is also considerable. Applying the superposition of epoches method, data for every day are available, in the average, for 67 events.

A similar result was obtained for earthquakes in the region of "Petropavlovsk-Kamchatsky" (Fig. 5). One can see an increase of $\bar{F}$ on the days $(-5), \ldots,(-3)$. Thereat, $\bar{F}$ surpasses the level of $95 \%$ of the reliability interval. The superposi-

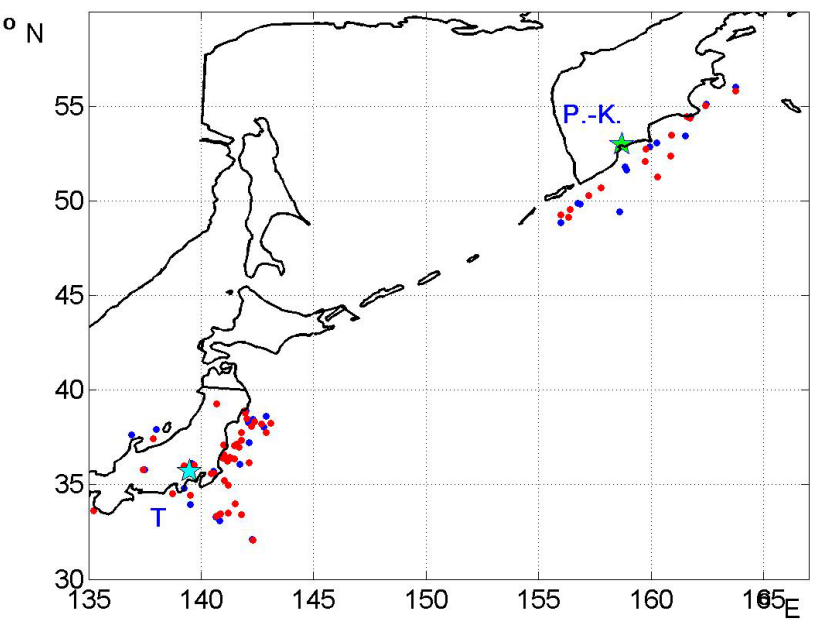

Fig. 8. Schematic disposition of earthquakes and stations. T "Tokyo" and P.-K. - "Petropavlovsk-Kamchatsky".

tion of epoches method is used for data with, on the average, 24 events for one day. The Figs. 6 and 7 show the results of the calculation of $\bar{F}$ for weaker earthquakes with magnitudes $5.0<M \leq 5.5$ registered by the stations "Tokyo" and "Petropavlovsk-Kamchatsky", respectively.

The schematic disposition of earthquakes and stations is shown in Fig. 8. Red points describe earthquakes, which show increasing foF $23-5$ days before the event. It has to be mentioned here, that in the Japanese Pacific Ocean region about 3-5 days before earthquakes with magnitudes $M>6$, changes of the phase and/or the amplitude of signals of VLF $(3-30 \mathrm{kHz})$ and $\mathrm{LF}(30-300 \mathrm{kHz})$ sounding experiments on the ground and using satellites were observed (Rozhnoi et al., 2006, 2007a).

The reliability interval is calculated modeling the background distribution with the help of a random process. It is assumed, that the earthquakes are homogeneously distributed within the observation time interval. Using a generator of random numbers, days of virtual earthquakes are chosen. The number of virtual earthquakes equals the number of real ones. Then, the superposition of epoches method is applied to the virtual earthquakes in the same way as to the real earthquakes.

This procedure is repeated for a few thousands of series of virtual earthquakes. For such a series, one obtains a mean value. If one considers 300 series, one obtains 300 values which are distributed according to the normal distribution, as any mean value is the result of the action (averaging) of many factors with limited amplitude. The normal distribution has its mean value and its standard deviation std. The standard deviation depends on the number of elements of the series, the more virtual earthquakes occur, the smaller is the standard deviation. If the number of series is sufficiently high, that means if it amounts to a few hundreds, the 
standard deviation does not depend on the number of series. Empirically, the number of series is chosen in such a way that one hundredth of std. does not change if one increases the number of series further (for instance twofold).

During the random choice of the virtual earthquakes it may happen, that the number of data is very small for the superposition of epoches. It may be, for instance, that all intervals of $(-15,+15)$ days occur during the maximum of the 11 -years solar cycle, and the condition $W<100$ is not satisfied. Therefore, only such series are further analysed, for which the number of "days with data" is sufficiently high. On the other hand, it may also happen that within the randomly chosen intervals no day has to be neglected, that means for all days the conditions $W<100$ and $\Sigma K_{p}<30$ are satisfied. Such a situation is also rather unrealistic. In the present work, studied are only such series of virtual earthquakes, for which the number of "days with data" does not differ from the number of "days with data" of the series of real earthquakes by $20 \%$.

Thus, there are so many series studied, that the mean and mean square values of the variations do not change if one further increases the number of series. In Figs. 5-8, the mean values are presented by thin full lines. The sum of the mean and two mean square values (mean +2 std), which equals $95 \%$ of the level of reliability, is shown by a dashed line.

The aim of the authors is to determine general laws of the behaviour of earthquakes, and not to present a general method of prognosis. Investigating earthquakes with foreshocks, it is assumed that the seismo-ionospheric effect occurs because of the main earthquake, and possible effects of the foreshocks are neglected. Such an approach may decrease the seismo-ionospheric effect, but guarantees a homogeneous handling.

Next, to investigate strong earthquakes with $M>5.5$ appearing at larger distances from the vertical sounding station with $500<R<1000 \mathrm{~km}$, intervals of days $(-7,+7)$ related to earthquakes with $M>5.5$ and $R<500 \mathrm{~km}$ are neglected to bypass the influence of nearer earthquakes. In case of earthquakes with $500<R<1000 \mathrm{~km}$ near "Tokyo", a small increase of $\bar{F}$ before the events is found, but it is statistically insignificant. Around "Petropavlovsk-Kamchatsky" only 10 earthquakes with $500<R<1000 \mathrm{~km}$ happened, so a statistical analysis was impossible.

Further, to study the effect for weaker earthquakes, intervals of days $(-7,+7)$ related to earthquakes with $M>5.5$ and $R<1000 \mathrm{~km}$ are omitted during the analysis. Investigating earthquakes with $5.0<M<5.5$ and $R<500 \mathrm{~km}$, it was found that the observation time of the maximum growth of $\bar{F}$ was different for "Tokyo" and "Petropavlovsk-Kamchatsky". In case of "Tokyo", about 5 days before the earthquake, $\bar{F}$ rises essentially. On the other hand, for "PetropavlovskKamchatsky", only a weak increase of $\bar{F}$ at the $(-2)$ day is found. But one has to mention, that the number of earthquakes with $5.0<M<5.5$ is small near "Petropavlovsk-

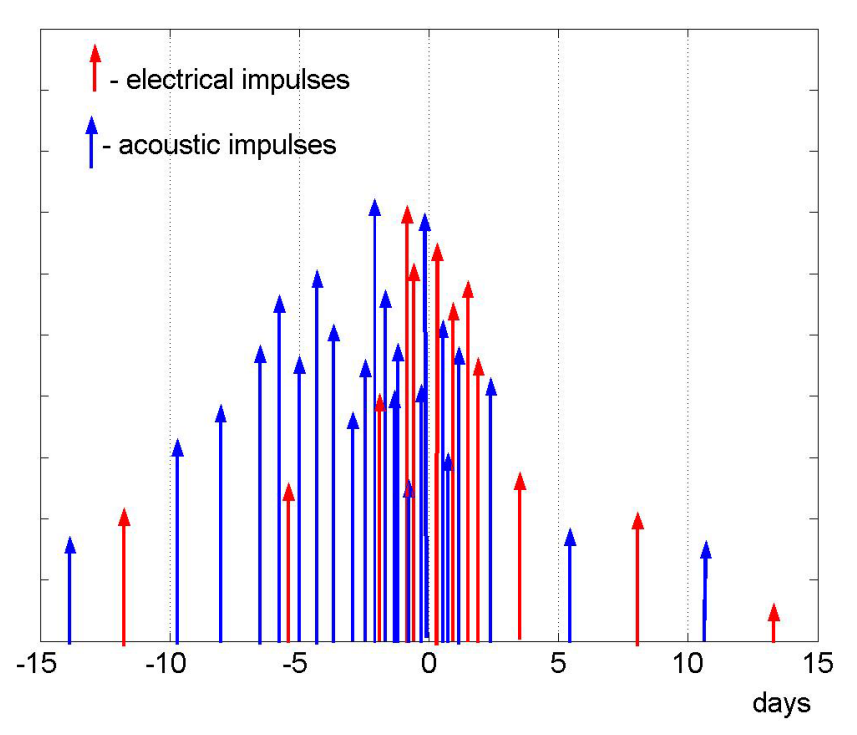

Fig. 9. Scheme of the increase of the number and amplitude of electrical and acoustical disturbances caused by processes of earthquake preparation.

Kamchatsky". The decrease of $\bar{F}$ after the earthquakes with $5.0<M<5.5$ is statistically unimportant.

\section{Discussion of the results and conclusions}

In the present work it is shown, that about 3-6 days before earthquakes with $M>5.5$ one finds, on the average, an essential increase of the foF 2 frequency. Then, there exists a tendency that the foF 2 values decrease again until the earthquake. The phenomenon is obtained at distances from the epicenters smaller than $500 \mathrm{~km}$. Also in case of weaker earthquakes with $5.0<M<5.5$ one obtains first an increase of foF 2 , and then a decrease towards the time of the event, but the characteristic time scale of the foF 2 decrease is smaller.

To explain the foF2 increase about 3-6 days before earthquakes, one may assume that in the F-layer rare impulses of neutral particles moving upward occur - because of acoustic pulses propagating upward (Rozhnoi et al., 2007b) and/or because of variations of the electrical field and a mosaiclike heating in the atmosphere (Mareev et al., 2002). One can assume that there are several physical mechanisms by which the lithosphere-ionosphere coupling is actually implemented (Liperovsky et al., 2008). The processes of upstreaming plasma cause a decrease of the recombination, and thus an increase of the maximum plasma density of the layer, that means of foF 2 .

Closely to the event (one day before the shock), spikes of radon pollution into the atmosphere are possible, and the frequency of disturbances of various nature increases. The radon causes non-stationary ionization processes, and consequently an increase of the electrical conductivity in 
the atmosphere (Sorokin and Chmyrev, 1998; Pulinets et al., 2000; Liperovsky et al., 2005; Sorokin et al., 2006). Correspondingly, also the vertical electric currents and the mean ionospheric temperature grow. The heating process becomes predominant and causes a diffusionary smearing out of the maximum of the electron density of the F2-layer about one day, or about two days, before and after strong earthquakes.

Thus one may assume that there are two processes of litosphere-ionosphere coupling before earthquakes. The first process is predominant 3-6 days before a shock and, the second one, one day before and one day or two days after a shock. During the first process episods of upstreaming ionospheric plasma flows, a decrease of the recombination and an increase of foF 2 take place. During the second process the upstreaming plasma flow also occurs, but the overwhelming processes are the heating and the diffusionary smearing out of the maximum of the electron density of the F2-layer (see Fig. 9).

In different cases, one has to do with different predominant processes. In the equations describing the behaviour of the plasma density before earthquakes (Ivanov-Kholodny and Mikhailov, 1990) different terms play the main role. Under every special condition the resulting effect is not only determined by the transfer of energy causing the heating process, but also by the orientation and value of the mean electric field, by the speed of the plasma heating and its convection from the area of increased pressure, by the wind system and by the distance between the studied region and the source of the disturbance.

Edited by: M. Contadakis

Reviewed by: J.-J. Berthelier and another anonymous referee

\section{References}

Dobrovolsky, I. R., Zubkov, S. I., and Myachkin, V. I.: Estimation of the size of earthquake preparation zones, Pageoph., 117, 1025-1044, 1979.

Gaivoronskaya, T. V.: Ionospheric variations in seismo-active regions, Fiz. Zemli, 3, 56-60, 2005.

Gokhberg, M. B., Gershenson, N. I., Gufeld, I. L., Kustov, A. V., Liperovsky, V. A., and Khusamiddinov, S. S.: On the possible effects of the influence of electric fields of seismic origin on the ionosphere, Geomagn. Aeron., 24(2), 217-222, 1984.

Gokhberg, M. B., Gufeld, I. L., and Liperovsky, V. A.: Electromagnetic precursors in the system of earthquake prediction: search, problems, Vestn. AN. SSSR, 3, 43-54, 1987.

Gokhberg, M. B., Kustov, A. V., Liperovskaya, R. Kh., Liperovsky, V. A., Kharin, E. P., and Shalimov, S. L.: Perturbations of the ionospheric F-layer prior to strong earthquakes, Izvestiya. Physics of the Solid Earth, 24, 4, 254-260, 1988.

Gokhberg, M. B., Pilipenko, V. A., and Pokhotelov, O. A.: On seismic precursors of earthquakes, Izv. AN SSSR, Fiz. Zemli, 10, 17-21, 1983.
Hobara, Y. and Parrot, M.: Ionospheric perturbations linked to a very powerful seismic event, J. Atmos. Terr. Phys., 67, 677-685, 2005.

Ivanov-Kholodnyi, G. S. and Michailov, A. V.: Prognosing the state of the ionosphere (determined approach), Gidrometeoizdat, Leningrad,190 pp., 1990.

Khakimov, F. K., Liperovsky, V. A., Shalimov, S. L., Alimov, O. A., Liperovskaya, R. K., and Roubtzov, L. N.: On disturbances in the ionosphere before some earthquakes in Tadshikistan in 1987, Dokl. AN Tadj. SSR, 32(12), 824-828, 1989.

Korsunova, L. P. and Hegai, V. V.: Seismo-ionospheric effects of strong core earthquakes in the Pacific, Geomagn. Aeron., 45(5), 665-671, 2000.

Liperovsky, V. A., Alimov, O. A., Shalimov, S. L., Gokhberg, M. B., Liperovskaya, R. K., and Saidshoev, A.: Investigation of the F-layer of the ionosphere before earthquakes, Fiz. Zemli., 12, 77-86, 1990.

Liperovsky, V. A., Meister, C.-V., Liperovskaya, E. V., Davidov, V. F., and Bogdanov, V. V.: On the possible influence of radon and aerosol injection on the atmosphere and ionosphere before earthquakes, Nat. Hazards Earth Syst. Sci., 5, 7830-789, 2005, http://www.nat-hazards-earth-syst-sci.net/5/7830/2005/.

Liperovsky, V. A., Pokhotelov, O. A., Meister, C.-V., and Liperovskaya, E. V.: Physical models of coupling in the lithosphereatmosphere-ionosphere system before earthquakes, Geomagn. Aeronomy, 48(6), 795-806, 2008.

Liu, J. Y., Chen, Y. I., Chuo, Y. J., and Chen, C.S.: A statistical investigation of preearthquake ionospheric anomaly, J. Geophys. Res., 111, A05304, doi:10.1029/2005JA011333,2006, 2006.

Mareev, E. A., Iudin, D. I., and Molchanov, O. A.: Mosaic source of internal gravity waves associated with seismic activity in: Seismo-Electromagnetics: Lithosphere-Atmosphere-Ionosphere Coupling, edited by: Hayakawa, M. and Molchanov, O., TERRAPUB, Tokyo, 335-342, 2002.

Ondoh, T.: Seismo-ionospheric phenomena, Adv. Space Res. 26(8), 1267-1272, 2000

Pulinets, S. A., Boyarshuk, K. A., Hegai, V. V., Kim, V. P., and Lomonosov, A. N.: Quasielectrostatic model of atmospherethermosphere-ionosphere coupling, Adv. Space Res., 26(8), 1209-1218, 2000

Rios, V. H., Kim, V. P., and Hegai, V. V.: Abnormal perturbations in the F2 region ionosphere observed prior to the great San Juan earthquake of 23 November 1977, Adv. Space Res., 33, 323-327, 2004.

Rozhnoi, A., Molchanov, O., Solovieva, M., Gladyshev, V., Akentieva, O., Berthelier, J. J., Parrot, M., Lefeuvre, F., Hayakawa, M., Castellana, L., and Biagi, P. F.: Possible seismo-ionosphere perturbations revealed by VLF signals collected on ground and on a satellite, Nat. Hazards Earth Syst. Sci., 7, 617-624, 2007, http://www.nat-hazards-earth-syst-sci.net/7/617/2007/.

Rozhnoi, A., Solovieva, M., Molchanov, O., Biagi, P.-F., and Hayakawa, M.: Observation evidences of atmospheric Gravity Waves induced by seismic activity from analysis of subionospheric LF signal spectra, Nat. Hazards Earth Syst. Sci., 7, 625628, 2007 http://www.nat-hazards-earth-syst-sci.net/7/625/2007/.

Rozhnoi, A. A., Solovieva, M. S., Molchanov, O. A., Chebrov, V., Voropaev, V., Hayakawa, M., Maekawa, S., and Biagi, P. F.: Preseismic anomaly of LF signal on the wave path Japan-Kamchatka 
during November-December 2004, Phys. Chem. Earth, 31, 422427, 2006.

Silina, A. S., Liperovskaya, E. V., Liperovsky, V. A., and Meister, C.-V.: Ionospheric phenomena before strong earthquakes, Nat. Hazards Earth Syst. Sci., 1, 113-118, 2001,

http://www.nat-hazards-earth-syst-sci.net/1/113/2001/.

Singh, B., Kushwah, V., Singh, O. P., Lakshmi, D. R., and Reddy, B. M.: Ionospheric perturbations caused by some major earthquakes in India, Phys. Chem. Earth, 29, 537-550, 2004.

Sorokin, V. M. and Chmyrev, V. M.: Modification of the ionosphere by seismic related electric field, Seismo-Electromagnetics, Tokyo. Terrapub, 805-818, 1998.
Sorokin, V. M., Yashenko, A. K., and Hayakawa, M.: Formation mechanism of lower-ionospheric disturbances by the atmosphere electric current over a seismic region, J. Atmos. Sol.-Terr. Phy., 68, 1260-1268, 2006. 